Першина Т.А., Федин С.В.

Практика повышения энергоэффективности предприятий теплоснабжения как фактора социальноэкономического развития города

\author{
Pershina T.A., Fedin S.V. \\ The practice of energy efficiency of heat supply enterprises as a \\ factor of socio-economic development of the city
}

В настоящее время в отрасли теплоснабжения РФ наблюдаются негативные тенденции, такие как нарастающий износ, устаревание фондов, недостаточность средств на проведение мероприятий по энергосбережению. Данная ситуация требует принятия мер по решению вышеуказанных проблем и обеспечению надлежащего качества услуг теплоснабжения. $B$ статье представлены результаты обоснования целесообразности реконструкции системы теплоснабжения предприятия ОАО

«КамышинТеплоЭнерго» за счет инвестиционной составляющей в утвержденных тарифах на услуги теплоснабжения

Ключевые слова: теплоснабжение, энергосбережение, инвестищионная составляющая, реконструкция, качество

\section{Першина Татьяна Александровна}

Кандидат экономических наук, доцент

Волгоградский государственный архитектурностроительный университет

г. Волгоград, ул. Академическая, 1

\section{Федин Сергей Владимирович}

Магистр

Волгоградский государственный архитектурностроительный университет

г. Волгоград, ул. Академическая, 1
Currently, the RF heating industry observed negative trends, such as rising depreciation, obsolescence of funds, lack of funds for energy efficiency measures. This situation requires the adoption of measures to address these problems and ensure the quality of heat supply services. The article presents the results of study feasibility of reconstruction of heat supply enterprises of "KamyshinTeploEnergo" due to the investment component in the approved tariffs for heating

Key words: heating, energy savings, the investment component, reconstruction, quality

\section{Pershina Tatiana Alexandrovna}

Candidate of Economic Sciences, Associate Professor Volgograd state university of architecture and civil engineering

Volgograd, Akademicheskaya st., 1

\author{
Fedin Sergey Vladimirovich \\ Master \\ Volgograd state university of architecture and civil \\ engineering \\ Volgograd, Akademicheskaya st., 1
}

В настоящее время Россия по-прежнему остаётся в десятке государств по высокому уровню износа основных производственных фондов (ОПФ). Данный показатель, по сведениям международных экономических организаций, 
оценивается, как минимум в 50\% (рис.1). В то же время, по группе БРИКС степень износа ОПФ не превышает 35\% [1].

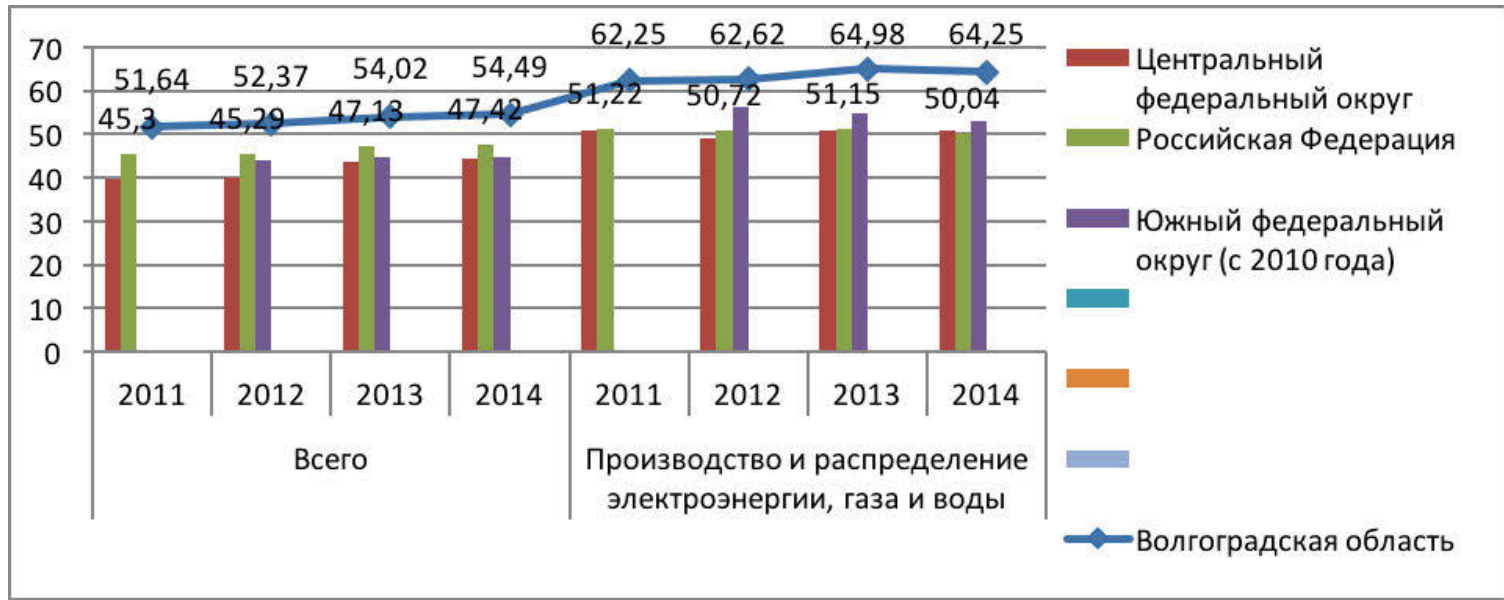

Pис. 1. Степень износа основных фондов на конец года по полному кругу организаций (процент)

На данный момент в Волгоградской области износ основных производственных фондов составляет около 65\%, что крайне негативно влияет на качество оказываемых услуг предприятиями ЖКХ [2]. Для решения обозначенных проблем необходимо выполнить кардинальную модернизацию/реконструкцию объектов отрасли с предоставлением долгосрочных займов банками или введением инвестиционной составляющей в тариф.

Реализация программы модернизации/реконструкции предприятий теплоснабжения позволит увеличить пропускную способность магистральных тепловых сетей на участках, которые сдерживают пропуск дополнительных мощностей для подключения в дальнейшем новых объектов, получить дополнительные тепловые мощности, перенаправить поток тепловой энергии для оптимизации работы ТЭЦ [3]. Также в программу необходимо включить мероприятия, снижающие потери тепла и повышающие эффективность использования топливно-энергетических ресурсов (рис. 2).

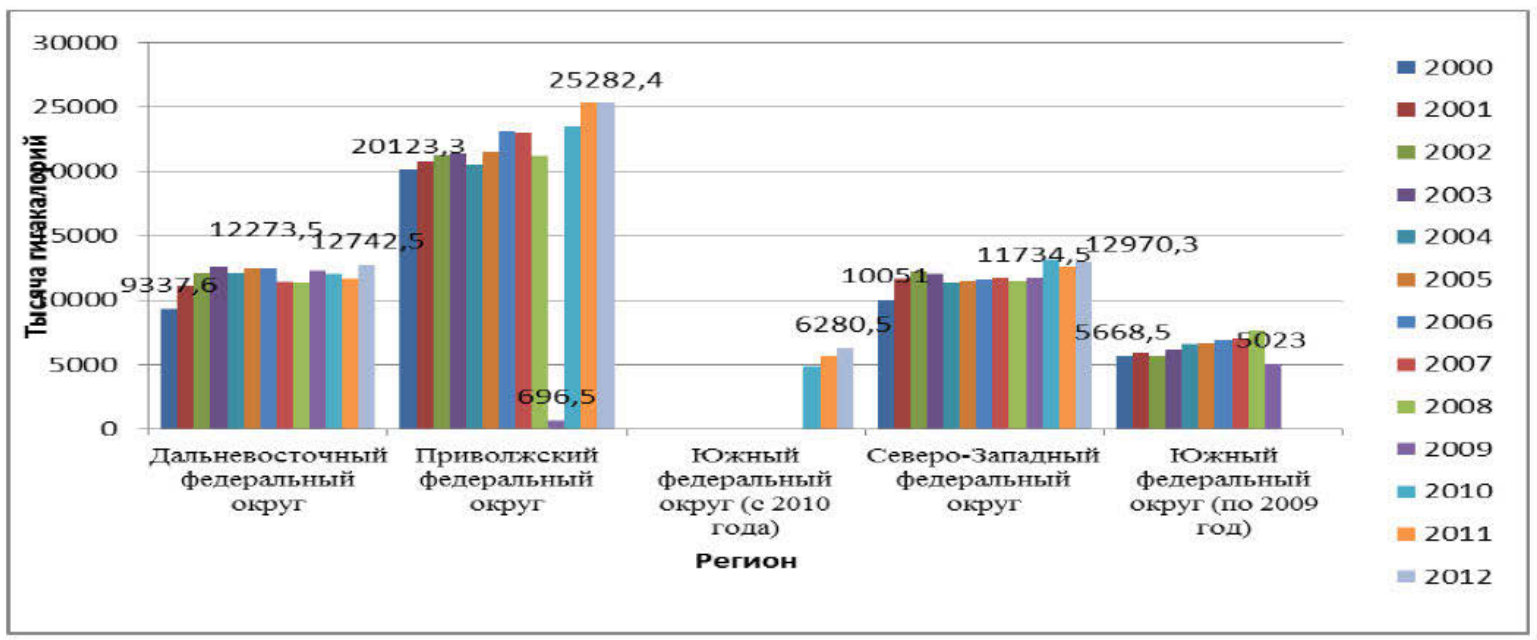

Pис. 2. Потери тепловой энергии за исследуемый период 
Практическое обоснование программы реконструкции на примере предприятия теплоснабжения

ОАО «КамышинТеплоЭнерго» осуществляет регулируемые виды деятельности, а именно - производство и передачу тепловой энергии. Предприятие не может быть прибыльным, поскольку тариф на тепловую энергию подлежит государственному регулированию в соответствии с полномочиями органа исполнительной власти субъектов Российской Федерации в области государственного регулирования тарифов [4].

\section{Таблица 1. Экономические показатели деятельности предприятия ОАО «КамышинТеплоЭнерго»}

\begin{tabular}{|c|c|c|c|c|c|c|c|}
\hline \multirow[t]{2}{*}{ Период } & \multicolumn{2}{|c|}{ Доходы, тыс. руб. } & \multicolumn{3}{|c|}{ Капитал, тыс. руб. } & \multicolumn{2}{|c|}{$\begin{array}{c}\text { Заемный капитал, тыс. } \\
\text { руб. }\end{array}$} \\
\hline & Выручка & $\begin{array}{c}\text { Чистая } \\
\text { прибыль }\end{array}$ & $\begin{array}{l}\text { Валюта } \\
\text { баланса }\end{array}$ & $\begin{array}{l}\text { Собств. } \\
\text { капитал }\end{array}$ & $\begin{array}{l}\text { Основные } \\
\text { средства }\end{array}$ & $\begin{array}{l}\text { Долгосроч- } \\
\text { ный }\end{array}$ & $\begin{array}{c}\text { Краткосроч- } \\
\text { ный }\end{array}$ \\
\hline 2013 & 167819 & -114527 & тыс. руб. & 530000 & $\begin{array}{c}523323 \\
\text { (на } 31.12 .2013)\end{array}$ & - & - \\
\hline 2014 & 671117 & -81209 & тыс. руб. & 530000 & $\begin{array}{c}525754 \\
\text { (на } 31.12 .2014)\end{array}$ & - & - \\
\hline 2015 & 752553 & - 120295 & тыс. руб. & 530000 & $\begin{array}{c}530631 \\
\text { (на } 31.12 .2015)\end{array}$ & - & - \\
\hline
\end{tabular}

Таблица 2. Расчёт инвестиционной составляющей в тарифе на тепловую энергию

\begin{tabular}{|c|c|c|c|c|c|c|}
\hline Наименование показателей & $\begin{array}{l}\text { Ед. } \\
\text { изм. }\end{array}$ & $\begin{array}{c}2016 \\
\text { год }\end{array}$ & $\begin{array}{c}2017 \\
\text { год }\end{array}$ & $\begin{array}{c}2018 \\
\text { год }\end{array}$ & $\begin{array}{c}2019 \\
\text { год }\end{array}$ & $\begin{array}{c}2020 \\
\text { год }\end{array}$ \\
\hline \multicolumn{7}{|c|}{ Тариф на тепловую энергию } \\
\hline $\begin{array}{l}\text { Отпуск тепловой энергии потреби- } \\
\text { телям }\end{array}$ & $\begin{array}{l}\text { тыс. } \\
\text { Гкал }\end{array}$ & 459,928 & $\begin{array}{c}459,92 \\
8\end{array}$ & $\begin{array}{l}459,92 \\
8\end{array}$ & $\begin{array}{l}459,92 \\
8\end{array}$ & $\begin{array}{l}459,92 \\
8\end{array}$ \\
\hline $\begin{array}{l}\text { Сумма инвестиционных средств, } \\
\text { предусматриваемая на реализацию } \\
\text { программы за счёт инвестицион- } \\
\text { ной составляющей в тарифе на теп- } \\
\text { ловую энергию для потребителей }\end{array}$ & $\begin{array}{l}\text { тыс. } \\
\text { руб. }\end{array}$ & $\begin{array}{c}72 \\
419,87\end{array}$ & $\begin{array}{c}107 \\
346,43\end{array}$ & $\begin{array}{c}29 \\
061,37\end{array}$ & $\begin{array}{c}51 \\
534,08\end{array}$ & $\begin{array}{c}36 \\
928,97\end{array}$ \\
\hline $\begin{array}{l}\text { Инвестиционная составляющая } \\
\text { (без НДС) }\end{array}$ & $\begin{array}{l}\text { руб./ } \\
\text { Гкал }\end{array}$ & 157,46 & 233,40 & 63,19 & 112,05 & 80,29 \\
\hline $\begin{array}{l}\text { Ожидаемый тариф на тепловую } \\
\text { энергию (без НДС) }\end{array}$ & $\begin{array}{l}\text { руб./ } \\
\text { Гкал }\end{array}$ & 2135,58 & $\begin{array}{c}2 \\
270,71\end{array}$ & $\begin{array}{c}2 \\
428,34\end{array}$ & $\begin{array}{c}2 \\
591,44\end{array}$ & $\begin{array}{c}2 \\
752,35\end{array}$ \\
\hline $\begin{array}{l}\text { Ожидаемый тариф с учётом инве- } \\
\text { стиционной составляюей в та- } \\
\text { рифе на тепловую энергию (ожи- } \\
\text { даемый тариф с учётом средств на } \\
\text { реализацию инвестиционной про- } \\
\text { граммы) (без НДС) }\end{array}$ & $\begin{array}{l}\text { руб./ } \\
\text { Гкал }\end{array}$ & 2293,04 & $\begin{array}{c}2 \\
504,10\end{array}$ & $\begin{array}{c}2 \\
491,53\end{array}$ & $\begin{array}{c}2 \\
703,49\end{array}$ & $\begin{array}{c}2 \\
832,65\end{array}$ \\
\hline
\end{tabular}

Основным направлением повышения эффективности деятельности анализируемого предприятия является - отказ от нерентабельных котельных «Баня-1» и «Пл. Павших Борцов» и дальнейшая модернизация оборудования с 
использованием лучших наработок в области эффективного использования ресурсов и энергосбережения при реконструкции котельной «Исполком».

Реконструкция котельной «Исполком» позволит кардинально улучшить систему теплоснабжения и приведет к следующим изменениям:

- сокращению расходов тепловой энергии на собственные производственные нужды;

- сокращению потерь тепловой энергии в сетях;

- сокращению удельного расхода топлива и электроэнергии на выработку тепла;

- автоматизации управления технологическим оборудованием котельной, что позволит усовершенствовать организационную структуру обслуживания производством тепловой энергии.

Обеспечение финансовых потребностей для выполнения проектов реконструкции предусмотрено, в том числе и за счёт реализации услуг по теплоснабжению, в части планируемой в тарифе на тепловую энергию инвестиционной составляющей. Расчёт инвестиционной составляющей в тарифе на тепловую энергию на реализацию программы реконструкции представлен в таблице 2 .

Указанные изменения позволят снизить себестоимость производства тепловой энергии, а также обеспечат круглогодичное снабжение горячей водой (ГВС) потребителей.

Таблица 3. Прогнозные результаты реконструкция котельной "Исполком» с увеличением мощности и закрытием нерентабельных котельных "Баня-1» и «Пл.

Павших Борцов» организации ОАО «КамышинТеплоЭнерго»

\begin{tabular}{|c|c|c|c|c|c|}
\hline \multirow[t]{2}{*}{ № } & \multicolumn{3}{|c|}{ Наименование } & \multirow{2}{*}{$\begin{array}{c}\text { Ед. изм., без } \\
\text { НДС } \\
\text { тыс. руб. }\end{array}$} & \multirow{2}{*}{$\begin{array}{c}\text { Расчет } \\
34764,89\end{array}$} \\
\hline & \multicolumn{3}{|c|}{ Реконструкция котельной «Исполком» } & & \\
\hline $\begin{array}{l}\text { № } \\
\Pi / \Pi\end{array}$ & Показатель & Ед. изм. & $\begin{array}{l}\text { До рекон- } \\
\text { струкции }\end{array}$ & $\begin{array}{l}\text { После рекон- } \\
\text { струкции }\end{array}$ & $\begin{array}{c}\text { Экономия } \\
(+)\end{array}$ \\
\hline \multirow[t]{5}{*}{1} & $\begin{array}{l}\text { Расход топлива (при- } \\
\text { родный газ): }\end{array}$ & & & & \\
\hline & - котельная «Баня-1» & $\begin{array}{c}\text { тыс. } \\
\text { куб.м/год }\end{array}$ & 507,330 & & \\
\hline & $\begin{array}{l}\text { - котельная «Пл. Пав- } \\
\text { ших борцов» }\end{array}$ & $\begin{array}{c}\text { тыс. } \\
\text { куб.м/год }\end{array}$ & 651,763 & & \\
\hline & $\begin{array}{l}\text { - котельная «Испол- } \\
\text { ком» }\end{array}$ & $\begin{array}{c}\text { тыс. } \\
\text { куб.м/год }\end{array}$ & 379,104 & 891,353 & \\
\hline & $\begin{array}{l}\text { Итого с учётом рекон- } \\
\text { струкции котельной } \\
\text { «Исполком»: }\end{array}$ & $\begin{array}{c}\text { тыс. } \\
\text { куб.м/год }\end{array}$ & 1538,197 & 891,353 & 646,844 \\
\hline \multirow[t]{4}{*}{2} & Расход эл/энергии & & & & \\
\hline & котельная «Баня-1» & $\begin{array}{c}\text { тыс. } \\
\text { кВт.ч/год }\end{array}$ & 101,55 & & \\
\hline & $\begin{array}{l}\text { котельная «Пл. Пав- } \\
\text { ших борцов» }\end{array}$ & $\begin{array}{c}\text { тыс. } \\
\text { кВт.ч/год }\end{array}$ & 135,72 & & \\
\hline & $\begin{array}{l}\text { котельная «Испол- } \\
\text { ком» }\end{array}$ & $\begin{array}{c}\text { тыс. } \\
\text { кВт.ч/год }\end{array}$ & 45,66 & & \\
\hline
\end{tabular}




\begin{tabular}{|c|c|c|c|c|c|}
\hline & $\begin{array}{l}\text { Итого с учётом рекон- } \\
\text { струкции котельной } \\
\text { «Исполком» }\end{array}$ & $\begin{array}{c}\text { тыс. } \\
\text { кВт.ч/год }\end{array}$ & 282,93 & 282,93 & - \\
\hline 3 & $\begin{array}{l}\text { Тариф на топливо в } \\
2015 \text { г. }\end{array}$ & $\begin{array}{l}\text { тыс. руб./ } \\
\text { тыс. куб. м }\end{array}$ & & 5,36302 & \\
\hline 4 & $\begin{array}{l}\text { Тариф на эл/энергию } \\
\text { в } 2015 \text { г. }\end{array}$ & руб./кВт.ч & & 5,03 & \\
\hline 5 & $\begin{array}{l}\text { Изменение затрат на } \\
\text { топливо }\end{array}$ & тыс. руб./год & & & 3469,037 \\
\hline 6 & $\begin{array}{l}\text { Изменение затрат на } \\
\text { эл/энергию }\end{array}$ & тыс. руб./год & & & \\
\hline \multirow[t]{5}{*}{7} & $\begin{array}{l}\text { Затраты на персонал } \\
\text { (ФОТ+ЕСН): }\end{array}$ & тыс. руб./год & & & \\
\hline & - котельная «Баня-1» & тыс. руб./год & 441,78 & & \\
\hline & $\begin{array}{l}\text { - котельная «Пл. Пав- } \\
\text { ших борцов» }\end{array}$ & тыс. руб./год & 317,01 & & \\
\hline & $\begin{array}{l}\text { - котельная «Испол- } \\
\text { ком» }\end{array}$ & тыс. руб./год & 314,87 & & \\
\hline & $\begin{array}{l}\text { Итого с учётом рекон- } \\
\text { струкции котельной } \\
\text { «Исполком»: }\end{array}$ & тыс. руб./год & 1073,66 & 314,87 & 758,79 \\
\hline \multirow[t]{5}{*}{8} & $\begin{array}{l}\text { Эксплуатационные за- } \\
\text { траты (тех. обслужи- } \\
\text { вание, ремонт, экспер- } \\
\text { тиза, прочие прямые } \\
\text { расходы): }\end{array}$ & & & & \\
\hline & - котельная «Баня-1» & тыс. руб./год & 456,72 & & \\
\hline & $\begin{array}{l}\text { - котельная «Пл. Пав- } \\
\text { ших борцов» }\end{array}$ & тыс. руб./год & 334,59 & & \\
\hline & $\begin{array}{l}\text { - котельная «Испол- } \\
\text { ком» }\end{array}$ & тыс. руб./год & 451,10 & & \\
\hline & $\begin{array}{l}\text { Итого с учётом рекон- } \\
\text { струкции котельной } \\
\text { «Исполком»: }\end{array}$ & тыс. руб./год & 1242,41 & 453,34 & 789,07 \\
\hline 9 & $\begin{array}{l}\text { Годовой экономиче- } \\
\text { ский эффект }\end{array}$ & тыс. руб./год & & & 5016,90 \\
\hline 10 & Период окупаемости & лет & & & 6,9 \\
\hline
\end{tabular}

Реконструкция котельной «Исполком» с увеличением мощности и закрытием нерентабельных котельных: «Баня-1» и «Пл. Павших Борцов», приведет к снижению расхода тепловой энергии на собственные нужды; потерь тепловой энергии в сетях; удельного расхода топлива и электроэнергии; а также обслуживающего персонала на 10 человек.

Реализация программы сопряжена с рядом потенциальных рисков, таких как превышение фактической стоимости мероприятий над плановой. Причины:

- изменения в законодательстве Российской Федерации;

- фактический уровень инфляции, превышающий уровень инфляции, учтенный при планировании Программы;

Также возможен недостаток финансовых средств, при реализации мероприятий Программы. Причины: 
- временные разрывы между периодом поступления денежных средств от реализации услуг со сроками финансирования Проектов (превышающие запланированные);

- неполнота оплаты потребителями услуг по теплоснабжению;

- неточность прогнозирования стоимости работ для реализации Программы.

Еще одним риском является несвоевременность реализации мероприятий по реконструкции объектов по причине несвоевременного выполнения работ подрядными организациями. Из трёх вышеперечисленных факторов риска наиболее реальным представляется недостаточное финансовое обеспечение. Именно недостаточное или несвоевременное финансирование содержит угрозу срыва мероприятий [5]. Возмещение вышеуказанных расходов программы реконструкции невозможно за счёт использования собственных средств организации, полученных от регулируемого вида деятельности, т.к. неизбежно приведёт, в свою очередь, к срыву производственных программ по теплоснабжению и невозможности качественного предоставления ресурса потребителям тепловой энергии.

\section{Список используемых источников:}

1. Кураленко О.Г. Управление инновационным развитием промышленных предприятий на основе эффективного использования ресурсного потенциала: автореф. дис. ... канд. экон. наук. Брянск, 2012. $24 c$.

2. Борисова Н.И., Борисов А.В. К вопросу об энергоресурсосбережении и энергоаудите ЖКХ регионов России в новых экономических условиях // Актуальные проблемы экономики и менеджмента. 2014. №3(03).

3. Першина Т.А. Развитие системы управления энергозатратами на предприятиях жилищнокоммунальной сферы: дис. ... канд. экон. наук. Волгоград, 2006. 174 с.

4. URL: http://www.камышинтеплоэнерго.pф/raskrytie-informatsii

5. Беляев М.К., Максимчук О.В., Першина Т.А. Управление энергозатратами на предприятиях жилищнокоммунального хозяйства. Волгоград: ВолгГАСУ, 2009. 144 c.

(C) 2016, Першина Т.А., Федин С.В. Практика повышения энергоэффективности предприятий теплоснабжения как фактора социально-экономического развития города
(C) 2016, Pershina T.A., Fedin S.V.

The practice of energy efficiency of heat supply enterprises as a factor of socio-economic development of the city 